\title{
EDITORIAL
}

\section{LOS NUEVOS DESAFÍOS DE LA REVISTA CHILENA DE DERECHO}

Con ocasión de la edición de este nuevo número de la Revista Chilena de Derecho, he asumido la Dirección de nuestra publicación, acompañada del Doctor en Derecho Marcelo Barrientos en calidad de Secretario de Redacción de la Revista. Nos ayudarán también en esta tarea un equipo de ayudantes dedicados tanto a la edición en papel como a la edición electrónica, y nuestras secretarias administrativas y de producción, bajo la atenta mirada y el sabio consejo de un Comité de Redacción integrado por nuestro Decano y prestigiosos profesores de diversas especialidades de la Ciencia Jurídica, como asimismo asistidos por los lineamientos y luces que en tantos temas de importancia nos brindan los miembros de nuestro Comité Editorial.

El atractivo planteamiento de asumir la Dirección de la Revista Chilena de Derecho se relaciona estrechamente con cuatro años pasados como Directora de Investigación de la Facultad de Derecho UC. En efecto, la producción científica que busca difundir nuestra publicación encuentra su más importante fuente en las investigaciones de académicos y profesionales de las Facultades de Derecho del país y del extranjero y, por supuesto, ha buscado ser una vía expedita para que el conocimiento acumulado se haga asequible a todos y tenga un efecto multiplicador no solo en la comunidad jurídica nacional e internacional, sino también entre los alumnos de Derecho de pre y postgrado.

En ese sentido, la Revista será una continuación, confiamos que muy fructífera, de los planteamientos que hemos llevado adelante desde hace mucho tiempo, en orden a privilegiar tanto en el estudio como en el ejercicio de la profesión la idea que investigar es una necesidad de todos y un imperativo del desarrollo no solo disciplinar sino material del Derecho de cualquier país, único medio efectivo de avance, evolución y materialización de garantías, instituciones y principios.

Sin embargo, el ámbito de la investigación, de suyo pausado y reflexivo, que toma los tiempos necesarios en el decantamiento de problemas complejos, no puede ignorar el necesario dinamismo de la problemática jurídica y de los requerimientos que la ciudadanía hace al Derecho desde la perspectiva de los intereses y de las demandas sociales: Se debe legislar, se necesita fallar causas que revisten urgencia, se ha de dar adecuada protección a los derechos de las personas, precaver problemas, deslindar responsabilidades, y todo ello también es preocupación del Derecho y, por qué no decirlo, de una publicación que a él se dedica. Asumiendo esta realidad, a la vez de sostener que sin lugar a dudas la investigación y el estudio de excelencia son la base de una revista como la nuestra, hemos querido a partir de este número matizarla y, en lo posible enriquecerla, con la referencia a la contingencia, a la opinión y al devenir de la disciplina, a través de una sección de Crónicas y Ensayos, en la que nuestros lectores puedan encontrar comentarios breves y actualizaciones vinculados con el día a día del acontecer jurídico de 
nuestro país y también del Derecho Comparado. Ello, en conjunto a los comentarios de jurisprudencia y a las recensiones de obras destacadas, presentará a nuestro lector una gama de posibilidades que esperamos esté a la altura de sus expectativas.

Sin embargo, la diversificación e inclusión de nuestras formas de comunicación no es el único desafío de la Revista Chilena de Derecho en este nuevo período.

En efecto, consideramos que los importantes pasos y logros exhibidos por la Dirección anterior, que valoramos especialmente en el trabajo y la figura de nuestros antecesores, el profesor Alejandro Vergara Blanco y su equipo, son un destacado escalón desde el cual estamos obligados a buscar alturas mayores. En ese sentido, nuestra intención es dedicarnos especialmente a efectuar en nuestra publicación los necesarios esfuerzos de administración, actualización y ajuste a estándares internacionales que nos permitan el día de mañana poder aumentar nuestra inclusión en índices y catálogos internacionales, hacer llegar nuestra Revista a más públicos y entidades y, sobre esa base, conseguir transformarla en una publicación que cumpla la totalidad de los requisitos necesarios para su indización científica plena.

Esa tarea será posible, sin duda, trabajando sobre los firmes basamentos dejados por los académicos que nos han precedido y contando con la colaboración de nuestros árbitros y consejeros, además de la apreciable situación de encontrarnos ya en Scielo y de poder desarrollar un plan de acción en comunidad con los lineamientos que ofrece CONICYT a las revistas científicas chilenas.

Sin embargo, todo ello sería solamente una romántica posibilidad si no fuera por nuestros autores, que en cada número comparten con nosotros sus hallazgos, talento y dedicación, para poder brindárselo a nuestro público y suscriptores.

A todos ellos y a cada uno, gracias por la confianza depositada hasta ahora en la Revista Chilena de Derecho y gracias también por brindarnos un espacio en el que esta nueva Dirección intentará aportar, en la mayor medida de lo posible, a los fines que son colectivos y queridos por todos.

ÁNGELA ViVANCo MARTíneZ

Directora

Revista Chilena de Derecho 